\title{
Moral Behaviors and Economic Motives ----Evidence from China when the aged fall
}

\author{
Feng-gang $\mathrm{Lu}^{1, \mathrm{a}}$, Yin-ping Chen ${ }^{2, \mathrm{~b}}$ \\ ${ }^{1}$ School of Economics, Harbin University of Commerce, Harbin, Heilongjiang Province, China \\ ${ }^{2}$ the Practice Teaching Management Center, Harbin University of Commerce, Harbin, Heilongjiang \\ Province, China \\ alfg0202@163.com, ${ }^{\mathrm{b}}$ cyp0711@163.com
}

Keywords: Motive of Morality; Economic Motive; fall of the Aged; Moral Sentiment

\begin{abstract}
Helping behavior tendencies within members of the society are common, nevertheless "PENG-Yu" case, in 2006, surprisingly discourages the tendency in China and turns it around. This paper introduces the behaviors of the aged who fall and the passersby who see the fall of the aged into the economic framework. The moral sentiment comes into the utility function. Subject to certain constraints, the optimal solutions reflecting behaviors of relevant participants are obtained. Results show that the pattern of the passerby's behaviors is influenced by the passerby's moral sentiment and the choice of the old man. The choice of the old man is determined by the old man's moral sentiment, the love for his children, his children's income and the anticipated medical fees.
\end{abstract}

\section{Introduction}

In 2006, there was a case in Nanjing, China, called "PENG-Yu" case, which changed the pattern of behaviors of Chinese people when old people fall and need help. People (called "passersby" in this paper) who happen to see an old person fall are trapped in an embarrassing situation. There is the possibility of being accused of being responsible for the fallen person's accident if he helps the fallen one, while the passerby who didn't help the fallen one will not only feel unsatisfied with himself but also face the moral accusation by the society.

The paper is organized as follows. Section 2 describes the context and the hypothesis of the paper; Section 3 presents the process of solving for several optimization equations with constraints. Section 4 gives simple conclusions.

\section{Theoretical Framework}

\section{Hypotheses}

(1) Every participant is rational.

(2) Moral behaviors can generate utility for participants.

(3) Consumption brings participants utility.

(4) The aged care about not only their own utility, but also their children's utility. (5) Children are required to pay for their parents' medical fees.

\section{Utility Functions of Participants}

The Utility Function of the Passerby

Set the utility function of the passerby as the Cobb-Douglas function:

$U_{p}=U_{p}\left(C_{p}, M_{p}\right)=\left(C_{p}\right)^{\alpha}\left(M_{p}\right)^{\beta}$

where $U_{p}$ denotes the utility of the passerby, $C_{p}$ is the consumption of the passerby, $M_{p}$ measures the level of morality of the passerby's behaviors, parameters $\alpha$ and $\beta$ measure the importance of consumption and morality in the passerby's utility function, $0<\alpha, \beta<1$.

The Utility Function of the Old Person

Set the utility function of the old person as the following: 


$$
U_{e}=U_{e}\left(C_{e}, M_{e}, U_{k}\right)=C_{e}{ }^{\eta} M_{e}{ }^{\mu} U_{k}{ }^{\sigma}
$$

where $\mathrm{U} \varepsilon$ is the utility of the old person, $\mathrm{C} \varepsilon$ is the consumption of the old person, $\mathrm{M} \varepsilon$ measures the level of morality of the old person, $U_{k}$ is the utility of the old person's children, parameters $\eta, \mu$ and $\sigma$ measure the importance of consumption, morality and his children's utility in the old person's utility function, $0<\eta, \mu, \sigma<1$.

The Utility Function of the Old Person's Children

Let the utility function of the children as a linear function:

$U_{k}=U_{k}\left(C_{k}\right)=\kappa C_{k}$

where $\mathrm{U}_{\mathrm{k}}$ is the children's utility, $\mathrm{C}_{\mathrm{k}}$ is the children's consumption, $\mathrm{k}$ is a coefficient, $\mathrm{k}>0$.

\section{The Optimization Process}

\section{The Passerby}

Case 1: the old person accusing the passerby of being responsible

If the old person accuses the passerby of being responsible, the passerby's utility, on one hand, will increase due to his morality, on the other hand, will decrease due to the loss of money which can turn into consumption.

The utility maximization problem of the passerby is:

$$
\begin{aligned}
& \max U_{p}=U_{p}\left(C_{p}, M_{p}\right)=\left(C_{p}\right)^{\alpha}\left(M_{p}\right)^{\beta} \\
& \text { s.t. } P_{1} C_{p}+P_{2} M_{P}=m
\end{aligned}
$$

where equation 5 is the constraint, $\mathrm{P}_{1}$ is the price of consumption, $\mathrm{P}_{2}$ can be interpreted as the medical fees, $\mathrm{m}$ is the income of the passerby.

Solve for the maximization problem and we can get:

$$
M_{p}=\frac{\beta}{\alpha+\beta} \frac{m}{P_{2}}
$$

For visual simplicity, we plot the passerby's choice set $\left(\mathrm{M}_{\mathrm{p}}, \mathrm{C}_{\mathrm{p}}\right)$ in a diagram as in the following Figure. Of course, the passerby will not help the old person if point $\mathrm{E}_{0}$ is at quadrant II.

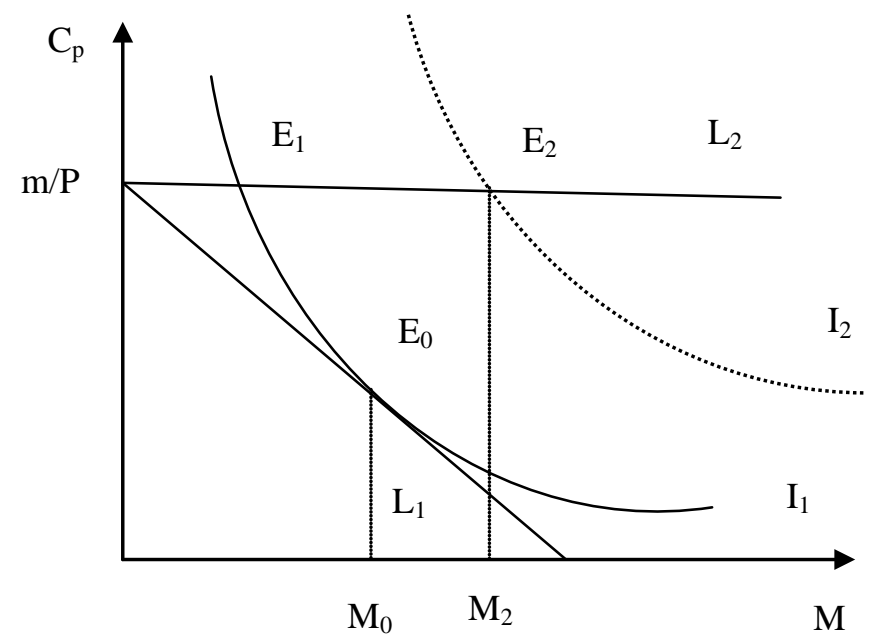

Case 2: the old person not accusing the passerby of being responsible

If the old person doesn't accuse the passerby of being responsible, the passerby will not suffer income loss when he helps the old person, and the tradeoff between morality and consumption disappears.

The budget constraint becomes:

$$
P_{1} C_{p}=m
$$


Similar process to case 1, we do the same monotonic transformation of function 1 . The utility maximization problem of the passerby is:

$$
\begin{aligned}
& \max \left(\alpha \ln C_{p}+\beta \ln M_{p}\right) \\
& \text { s.t. } P_{1} C_{p}=m
\end{aligned}
$$

Through the same progress we can get the solution of the problem:

$\beta=0$, or $M_{p}=+\infty$.

$\beta=0$ is not fit to expression 1 because $0<\beta<1$. So the second is the solution. That means the passerby will absolutely help the old person if the old person doesn't accuse him of being responsible.

It makes more sense to illustrate this on figure 1. From equation 7 we can get that the budget constraint line becomes a horizontal line i.e. $\mathrm{L}_{2}$. Line $\mathrm{L}_{2}$ cuts indifference curves infinite times (like point $E_{1}$ and point $E_{2}$ on Figure 1). If only the passerby chooses to behave more morally, the passerby will always achieve a higher level of utility. Under this circumstance, a rational man will absolutely always choose to behave more morally, which means the possibility that the passerby helps the old person is 1 .

\section{The Old Person}

Do the monotonic transformation of the old person's function, function2, and get,

$U_{e}\left(C_{e}, M_{e}, U_{k}\right)=\eta \ln C_{e}+\mu \ln M_{e}+\sigma \ln U_{k}$

The utility maximization problem of the old person is:

$$
\begin{aligned}
& \max \left(\eta \ln C_{e}+\mu \ln M_{e}+\sigma \ln U_{k}\right) \\
& \text { s.t. } \quad P_{1} C_{e}+P_{2} M_{e}=Y_{e}+\delta Y_{k} \\
& U_{k}=U_{k}\left(C_{k}\right)=\kappa C_{k}=\kappa(1-\delta) Y_{k}
\end{aligned}
$$

Solve the equations and get the solution:

$$
M_{e}=(-\delta) \cdot \frac{\mu}{\sigma} \cdot \frac{Y_{k}}{P_{2}}
$$

Neglect the part $(-\delta$ ) first. There are four variables in equation 12 to determine the old person's behavior of morality without the transfer of the income from the children, the sentiment of morality of the old person $(\mu)$, the care for his children's utility $(\sigma)$, the children's income $\left(Y_{k}\right)$ and the medical fees $\left(\mathrm{P}_{2}\right)$. The stronger the old person's sentiment of morality, or the more the children's income, the more likely the old person will tend to behave morally. The more the care for his children's happiness, or the higher fees of the medical treatment, the more likely the old person will tend to behave immorally.

The transfer of income from the children to the old person turns all things around here, $\lambda$, the Lagrange multiplier, is negative. We can infer the transfer of income from the children brings the old person negative utility according to the function of $\lambda$ in the Lagrangian. Because the old person loves his children and cares about the children's wellbeing, it is not a utility maximization choice to take the transfer of income from his children. Hence, the old person will try to make the transfer of income happen to the other participant, the passerby who helped him when the old person fell. Consequently, the old person has to make an immoral choice to accuse the passerby of being responsible.

\section{Conclusions}

It is a rational choice rather than a deterioration of morality that few people in China today offer help to an old person when the old person falls because Figure 1 shows, given the sentiment of morality ( $\beta$ is constant), a same passerby will behave quite differently as the responses to different choices the old person has made.

The main reason that an old person tends to behave immorally to accuse the passerby of being 
responsible under uncertainties is that the old person loves his children and tries to unload the responsibility from his children to pay the medical fees.

From the above analysis, we can get the conclusion that the right way to solve the problem is to work on the worries behind the choice of the aged, not to only give moral lecture on the young men, which is good but not enough.

\section{Acknowledgments:}

This paper is financially supported by SRFDP project (207233120001), Projects of the National Social Science Foundation of China(15BJL043), the research projects of the social science and humanity (7YJA790100) of the Ministry of Education of the People's Republic of China; and supported by the Research Initiating Fund for PhDs of Harbin University of Commerce (6DW012).

\section{References}

[1] Adam Smith. (2010). The Theory of Moral Sentiments. Whitrfish: Kessinger Publishing LLC.

[2] Becker G..(1974). A Theory of Social Interactions. The Journal of Political Economy, 82(6),1063-1093.

[3] Bernheim D., Shleifer A., Summers, L..(1985).The Strategic Bequest Motive.The Journal of Political Economics , 93(6),1045-1076.

[4] Croson, R. and Konow, J.. (2007). Double Standards: Social Preferences and Moral Biases. Working Paper in Social Science Research Network(SSRN980353).

[5] Dunfee, T. W.. (1998).The Marketplace of Morality: First Steps toward a Theory of Moral Choice. Business Ethics Quarterly, 8(1),67-85.

[6] Fang Jian-Guo. (207). Reviews on Preferences and Market Morality. Journal of Fuzhou University (Social Science), 2, 52-59. 